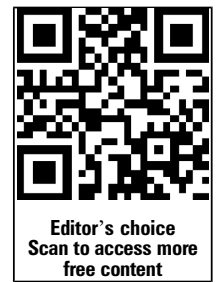

For numbered affiliations see end of article.

Correspondence to Professor Thomas Rösch, Department of Interdisciplinary Endoscopy, University Hospital Hamburg-Eppendorf,

Martinistr. 52, Hamburg 20246, Germany: t.roesch@uke.de

Received 4 July 2013 Revised 22 November 2013 Accepted 11 December 2013 Published Online First 3 January 2014
CrossMark

To cite: Anders $M$, Bähr $C$, El-Masry MA, et al. Gut 2014;63:1535-1543.

\title{
Long-term recurrence of neoplasia and Barrett's epithelium after complete endoscopic resection
}

\author{
Mario Anders, ${ }^{1}$ Christina Bähr, ${ }^{1}$ Muhammad Abbas El-Masry, ${ }^{1,2}$ Andreas H Marx, ${ }^{3}$ \\ Martin Koch, ${ }^{4}$ Stefan Seewald, ${ }^{1,5}$ Guido Schachschal, ${ }^{1}$ Andreas Adler, ${ }^{6}$ \\ Nib Soehendra, ${ }_{1}$ Jakob Izbicki, ${ }_{1}^{7}$ Peter Neuhaus, ${ }^{8}$ Heiko Pohl, ${ }_{1}^{9}$ Thomas Rösch $^{1}$
}

\section{ABSTRACT}

Background Current endoscopic therapy for neoplastic Barrett's oesophagus (BO) consists of complete resection/ablation of all Barrett's tissue including neoplastic lesions. Recurrence seems to be frequent after thermal therapy, such as radiofrequency ablation.

Objective To analyse long-term recurrence of neoplasia and BO after successful widespread endoscopic mucosal resection (EMR).

Design In a retrospective analysis, all patients undergoing widespread EMR of neoplastic BO between 2002 and 2007 at two referral centres were followed for at least 3 years after completion of endotherapy. Recurrence was diagnosed if neoplasia and/or BO were detected following previous successful complete removal, defined as at least two negative endoscopies and biopsies.

Results Ninety patients undergoing widespread EMR were included (mean age 63 years; 82 male), 58\% of whom underwent additional thermal ablation for minor residual disease. Complete eradication of neoplasia and Barrett's tissue was achieved in $90 \%$ of patients. On further follow-up (mean 64.8 months), recurrence of neoplastic and non-neoplastic BO was found in $6.2 \%$ and $39.5 \%$, respectively. Recurring neoplasia (3 adenocarcinomas, 1 low-grade and 1 high-grade dysplasia) were found after a median of 44 months (range 38-85) and could be retreated endoscopically. In a multivariate analysis, Barrett's length was the only factor significantly associated with recurrence (OR 2.73). Conclusions Even after seemingly complete endoscopic resection, recurrence of $\mathrm{BO}$ is frequent and independent of additional thermal therapy. Due to the possibility of neoplasia recurrence even after long disease-free intervals, follow-up should be extended beyond 5 years.

\section{INTRODUCTION}

Barrett's oesophagus (BO), the acquired replacement of the squamous epithelium lining of the distal oesophagus by columnar epithelium containing goblet cells, is a consequence of chronic gastroesophageal reflux. $\mathrm{BO}$ is considered to be a precancerous condition, and although the lifetime risk of malignant transformation in non-neoplastic $\mathrm{BO}$ is low, ${ }^{1}$ an increasing frequency of Barrett's-associated adenocarcinomas has been noted in recent decades. ${ }^{2}$ Patients with precursor lesions such as intraepithelial neoplasia ${ }^{3}$ and early-stage adenocarcinoma limited to the mucosa can be cured, as this disease stage is

\section{Significance of this study}

What is already known on this subject?

- Complete eradication of neoplastic Barrett's oesophagus (BO) by endotherapy includes focal mucosal resection and widespread ablation by thermal methods.

- Current management rests on radiofrequency ablation, which has recently been shown to have recurrence rates of up to $30 \%$ in the long term in registries partially including non-expert centres.

- Widespread endoscopic mucosal resection has also been shown to be highly effective, but is associated with high stricture rates; mid-term recurrence rates, however, seems to be equivalent to combined therapy.

\section{What are the new findings?}

- Complete eradication of neoplastic BO by widespread endoscopic mucosal resection, including thermal ablation of small residual Barrett's mucosa, also has a substantial long-term recurrence rate of minor non-dysplastic Barrett's tissue.

- Cancer recurrence is below $10 \%$ but can be found even after long periods without endoscopic-bioptic evidence of Barrett's or neoplasia.

How might it impact on clinical practice in the foreseeable future?

- Control of Barrett's-associated neoplasia by means of endotherapy is highly effective, but even after complete ablation of residual Barrett's tissue, recurrence requires continued surveillance. This should be extended beyond 5 years.

- Non-neoplastic BO recurs even after complete endoscopic resection; this is not affected by additional use of thermal methods for minimal residual disease. Mechanisms of recurrence have still to be elucidated.

associated with almost no risk of lymph-node metastasis. ${ }^{4}$ Therefore, endoscopic treatment ('endotherapy') represents a valuable new modality as it allows for organ preservation and is associated with a low rate of procedure-related morbidity. ${ }^{5}$ 
Currently, endotherapy comprises resective measures and ablative techniques, with different pros and cons for each of them. Endoscopic resection of the entire BO is associated with a high stricture rate. ${ }^{67}$ While combined resection and radiofrequency ablation (RFA) are considered recommended management, it does not provide tissue sampling of the entire $\mathrm{BO} .{ }^{8}$ The long-term consequences of such strategies, however, have rarely been evaluated. A limited number of studies have suggested that multimodal endoscopic treatment may be associated with recurrence of neoplasia. 5 Recently, three series from different centres with different expertise have reported variable but partially high recurrence rates of Barrett's epithelium after RFA. ${ }^{10-12}$ Thus, it could be speculated that complete endoscopic resection (also called widespread endoscopic mucosal resection, EMR) might lead to lower recurrence rates of $\mathrm{BO}$ and Barrett's-associated neoplasia compared with thermal ablation of residual Barrett's tissue after focal resection of visible neoplasia, which is currently the predominant management strategy.

The aim of the present study, therefore, was to analyse the long-term outcome of patients who had undergone successful resection of neoplastic $\mathrm{BO}$, defined as at least two negative endoscopies with biopsies showing no neoplasia or BO. The study also differentiated between recurrence of non-dysplastic BO and Barrett's-associated neoplasia.

\section{PATIENTS AND METHODS \\ Patients}

As part of a quality assurance programme, records from all patients treated endoscopically for neoplastic BO between 2002 and 2007 were retrieved from endoscopy and hospital databases. Different key word searches focusing on $\mathrm{BO}$ and various endoscopic treatment modalities, were conducted on the electronic databases of the pathology and endoscopy departments of two tertiary referral centres, in Berlin (2004-2007, complete BO endotherapy was not systematically performed at this centre prior to 2004) and in Hamburg (2002-2007).

Patients were included in the final analysis if they had undergone successful resection of neoplastic BO (defined as at least two negative endoscopies with biopsies showing no neoplasia or BO), and had at least 3 years of follow-up information available that included endoscopy and biopsy results. Patients were excluded if they underwent surgery following endotherapy, did not undergo intended $\mathrm{BO}$ eradication, or had incomplete follow-up ( $<3$ years, no endoscopy and/or biopsy results).

\section{General study approach}

Patients were primarily treated by EMR in one or mostly two sessions (at intervals of 4-12 weeks). Minor areas of remaining Barrett's tissue were ablated by thermal methods thereafter, until complete macroscopic and microscopic (biopsy) eradication of all Barrett's tissue.

Information on the length of the Barrett's segment and the size/appearance and histology of lesions was taken from the patients' charts and endoscopy reports. Histology was read by experienced gastrointestinal pathologists at both centres.

After the initial EMR session, histological specimens were analysed with respect to tumour grading, infiltration depth (mucosa or submucosa sm1-3) and tumour-free basal tumour margins (R0). If the histological analysis identified the lesion as low risk (mucosal infiltration, G1/2, L0 V0, basal R0) or the patients were either unfit for surgery or did not want to undergo surgery as recommended, endotherapy was continued primarily by resection, unless this was refused by the patient. If a stricture was found that required (repeated) dilation for resolution of dysphagia, these dilation sessions were included in the treatment period.

Of the cases with intended complete resection, patients in whom this was achieved were further followed by endoscopy and biopsy. Failure and possible reasons for failure of complete BO eradication were also documented. Patients then underwent regular follow-up endoscopies at intervals of 6-24 months, depending on the time since the EMR procedure and individual physician preferences. At every endoscopy, biopsies should be taken from the normal-looking neo-Z-line and from the neo-squamous epithelium, as well as from any visible lesions. Only patients with endoscopy follow-up, including biopsies of at least 3 years after completion of endotherapy, including dilation of strictures, were included in this long-term follow-up study.

The study was approved by the local ethics committee for publication of quality assurance data (Hamburg Chamber of Physicians WF 049/13) and patient consent for follow-up information to be used for research purposes and publication was obtained in all cases.

\section{Techniques of endotherapy}

EMR technique

At the initial session, patients were primarily treated by EMR of visible lesions using widespread piecemeal EMR. Olympus gastroscopes (GIF-140-180 series; Olympus; Hamburg, Germany) were used. Most procedures were performed using the piecemeal cap (Olympus) method by Inoue, ${ }^{13}$ or multiband ligation (Cook Medical, Mönchengladbach, Germany). ${ }^{14}$ In Hamburg, EMR was carried out by multiple snare resections (Olympus) at the start of the study period. The initial procedure always aimed at complete resection of all visible neoplastic tissue, together with semicircumferential resection of the affected Barrett's side. In a few cases with short Barrett's segments, circumferential resection was also done.

Saline was used for submucosal injection and elevation, and adrenaline injection and coagulation forceps, as well as clipping in more severe cases, were used for haemostasis after each resection. If perforation occurred, immediate closure was attempted by the use of clips, and if this failed, patients were sent to surgery.

At subsequent follow-up endoscopy, any remaining Barrett's tissue was sought, biopsied and resected or ablated (see below); this procedure was repeated if necessary.

\section{Ablation methods}

Endoscopic resection was the mainstay of therapy in this series. For small residual Barrett's areas not amenable to endoscopic resection, either because they were too small or were in areas of scarring or at resection margins, argon plasma coagulation (APC) was used (settings of 40-60 W; Erbe Elektromedizin, Tübingen, Germany). In four cases, additional focal RFA (Covidien, Sunnyvale, California, USA) was performed.

\section{Endoscopic dilation of post-therapeutic strictures}

Endoscopic bougies (US Endoscopy, Mentor, Ohio, USA) of increasing sizes were used over a guide-wire in cases of symptomatic strictures, and patients were told to present early in case of incipient swallowing difficulties. The number of dilation sessions was determined by relief of dysphagia reported by patients; usually, it was attempted to achieve at least sufficient dilation to allow a conventional endoscope to pass the stricture. The number of sessions and possible complications were documented. We decided to start the follow-up period for the study 
after the end of the dilatation period, since assessment of endotherapy effect including biopsies is only possible with restoration of the lumen to allow passage of conventional endoscopes.

\section{Further endoscopic follow-up}

Since this is a retrospective analysis, there was no uniform follow-up protocol. However, patients were advised to present for follow-up every 6 months after termination of treatment for the first 1-2 years, and thereafter annually. Endoscopy was performed in search for residual $\mathrm{BO}$ or neoplastic tissue, and biopsies were taken from these areas and, additionally, routinely around the neo $\mathrm{Z}$ line. No systematic mapping (below, at and above the neo $\mathrm{Z}$ line) was, however, performed as in recent prospective protocols.

\section{Outcome parameters}

Primary outcomes

The primary outcome parameters were the rates of recurrence of neoplasia (low-grade and high-grade intraepithelial neoplasia (LGIN/HGIN) and cancer) and of Barrett's epithelium without neoplasia following successful complete removal of $\mathrm{BO}$ and neoplasia (defined as two negative follow-up endoscopies with biopsies that were negative for $\mathrm{BO}$ and neoplasia).

\section{Secondary outcomes}

The secondary outcome parameters were:

- The rate of patients with intended complete eradication of BO among all patients eligible for widespread EMR.

- The rate of patients with successful complete eradication of BO among all patients who underwent intended complete eradication.

- Factors influencing success and recurrence rates, such as age and sex of the patient, Barrett's length, type of neoplasia, methods and number of therapy sessions, occurrence of strictures.

- The rate of initial (during procedures) and postprocedural complications (eg, strictures), and complications occurring during treatment of complications.

- The number of sessions necessary for initial eradication of BO and neoplasia, and the number of dilation sessions required for strictures.

- The total treatment period (months) and the number of hospital stays before start of follow-up.

\section{Statistics}

The main outcome (rate of $\mathrm{BO}$ or neoplasia recurrence) is presented as a proportion with a $95 \%$ CI. For comparison of proportions we applied the $\chi^{2}$ test or the two-tailed Fischer's exact test when appropriate. Normally distributed variables were compared using the Student $t$ test and non-normally distributed the Mann-Whitney U test. To examine potential predictors of recurrence, we applied stepwise logistic regression analysis. Given the low number of patients with recurrence, we planned to include a maximum of four variables in the adjusted analysis. We first examined the following factors in univariate analysis: age, sex, long versus short BO (cut-off $3 \mathrm{~cm}$ ), neoplasia grade (cancer vs low-/high-grade intestinal neoplasia), type of endotherapy (resection technique; resection alone vs resection plus ablation of minor residual disease), number of treatment sessions, occurrence of strictures, duration of endotherapy, number of biopsies during follow-up, and time of follow-up. The factors that showed the strongest association with the outcome in univariate analysis, and that had a $\mathrm{p}$ value $\leq 0.20$ were then applied in the final regression model to compute adjusted ORs.

\section{RESULTS}

Patient inclusion and outcome data are shown in figure 1. Initially, 179 patients were selected from the endoscopy and histopathology databases of both university hospitals (University Hospital Hamburg-Eppendorf 2002-2007 and Charité University Hospital, Berlin 2004-2007). A total of 41 patients were excluded because they required secondary surgery after the first endotherapy session (39 due to high-risk lesions and/or incomplete resection with positive basal margins and two due to perforation during EMR). Of the remaining 138 patients, complete Barrett's eradication was not intended in six patients, mostly due to age and comorbid conditions.

Follow-up started after the end of the endotherapy period, which included completed widespread EMR, additional thermal therapy of minor residual disease and dilation of strictures. In 42 cases, this follow-up period was less than the 3-year period required for study inclusion (see figure 1). Of these, 21 patients died before reaching the 3-year follow-up period, but any link to Barrett's neoplasia could be excluded in eight patients due to information from referring physicians and/or relatives, and was unclear (although perhaps not likely) in 13, in a few cases due to missing consent of relatives to use the data. Insufficient follow-up data in the remaining 21 surviving patients was due to: follow-up period $<3$ years, endoscopies performed but no biopsies taken, endoscopy not performed or endoscopies were performed at other institutions and results were not available. Inclusion of these patients would have meant that only visible and/or advanced cancers that caused symptoms would have been recorded. This group of excluded patients included one female patient who had a very long treatment period (72 months) and negative follow-up results after this period, but whose follow-up period was only 30 months.

A total of 90 patients were included in the final analysis of this study, and their basic data are shown in table 1 . The characteristics of this study group were similar to the total patient group undergoing EMR for neoplastic BO $(n=179)$ (study group vs total group: mean age 63 vs 64 years; male to female ratio $10: 1$ vs $10: 1$; use of EMR alone $42.2 \%$ vs $53.0 \%$ ). Of these 90 patients, $52(57.8 \%)$ required additional thermal therapy of minor residual disease, and 43 (47.8\%) experienced strictures and underwent dilation by endoscopic bougienage over a mean period of 7.9 weeks. Eradication was finally achieved for neoplastic tissue in all 90 patients. However, residual non-neoplastic $\mathrm{BO}$ was found in nine cases during one or several subsequent endoscopies, accounting for an initial success rate for complete $\mathrm{BO}$ eradication including neoplasia of 90\% (81/90).

During further follow-up of the 81 patients with initial successful complete eradication, only 44 (54.3\%) remained free of recurrence of $\mathrm{BO}$ and neoplasia. $\mathrm{BO}$ recurrence alone was found in 32 patients (39.5\%) and neoplasia recurrence alone was found in $5(6.2 \%)$. Details of the recurring neoplasias (3 adenocarcinomas, 1 HGIN and 1 LGIN), which were found after long disease-free intervals (median 44 months; 38, 42, 44, 56 and 85 months, respectively) are shown in figure 1 and table 2. Repeat endoscopic therapy was possible in all cases.

An additional analysis was performed correlating $\mathrm{BO}$ and neoplasia recurrence to the number of biopsies taken during follow-up endoscopies. Useful information about biopsy numbers, at least two subsequent follow-up endoscopies were available in $70 / 81$ cases. It was found that the mean number of 
Figure 1 Flow sheet showing the further course of patients treated for neoplastic Barrett's oesophagus.

Patients with neoplastic BE treated endoscopically 2002-2007 in Hamburg and Berlin $\mathrm{N}=179$

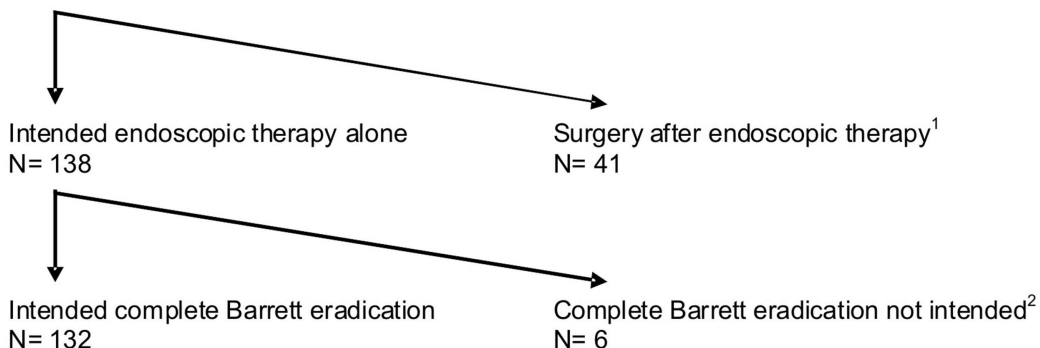

$N=132$

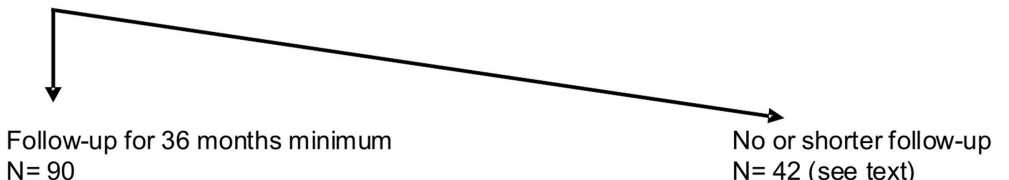
$\mathrm{N}=90$

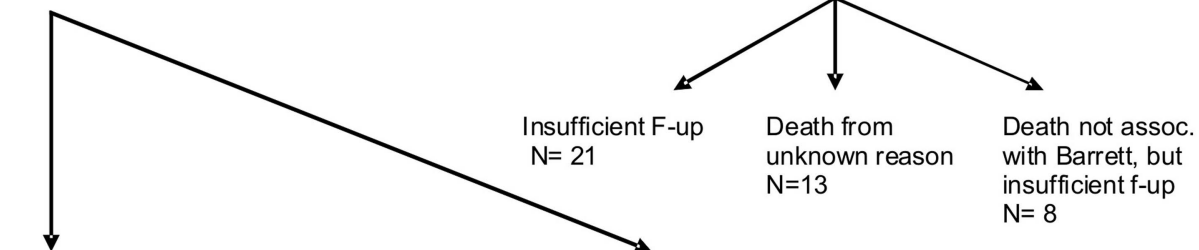

Complete eradication of Barrett and neoplasia ${ }^{3}$ Residual Barrett, no neoplasia $\mathrm{N}=81$ $\mathrm{N}=9$

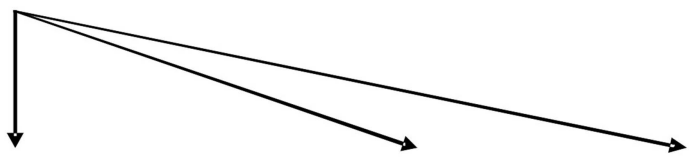

No recurrence of Barrett or neoplasia $\mathbf{N}=\mathbf{4 4}$ Recurrence of

(final therapeutic Barrett $\mathrm{N}=32$

Recurrence of success)

${ }^{1}$ reasons for surgery were tumor not fulfilling criteria for curative endotherapy $(n=39)$ or perforation $(n=2)$.

${ }^{2}$ reasons were mostly old age ( $>75$ years of age) and long Barrett $(8-13 \mathrm{~cm})$ without additional dysplasia $(n=4)$ patient refusal $(n=1)$ and old age, long Barrett and sm2-infiltration $(n=1)$; the latter came back with advanced recurrence and received an esophageal stent(see text)

${ }^{3}$ as defined by two subsequent negative endoscopies with biopsies during follow-up after the

termination of the therapeutic series (see text). Recurrence was defined if found thereafter

${ }^{4}$ after a mean of 44 months $(38,42,44,56,85$ months); 1 LGIN, 1 HGIN, 3 adenocarcinoma (see text)

biopsies did not significantly differ between patients displaying persistent absence of $\mathrm{BO}$ and those with $\mathrm{BO}$ or neoplasia recurrence (tables 3 and 4 ).

Patients with recurrence of neoplasia or $\mathrm{BO}$ were similar with respect to most patient, Barrett and treatment characteristics, neither with respect to resection versus combined endotherapy (resection plus thermal ablation) nor with respect to endoresection technique (table 3). Patients with recurrent disease more often had the initial diagnosis of cancer, had a higher number of treatment sessions, and a longer duration of treatment, however, none of these differences were significant. The only independent predictor of recurrence was Barrett length. More patients in the recurrence group had a long segment BO than in the group without recurrence, and in adjusted regression analysis (age, sex, BO length), patients with a long segment $\mathrm{BO}$ had an almost threefold increased risk of recurrence compared with those with a short-segment BO (table 4). Figures 2 and 3 show examples of cases without and with recurrences of $\mathrm{BO}$ and neoplasia. Recurrence of neoplasia was mostly located at the neo $\mathrm{Z}$ line or in two cases in the neosquamous epithelium, one as subsquamous recurrence, the other in small visible $\mathrm{BO}$ islands.
Recurrence of non-neoplastic BO was found mostly at the neo $\mathrm{Z}$ line 'tongue-shaped' (max extend $3 \mathrm{~cm}$ ) or as 'small islands' within the neosquamous epithelium.

Calculation of the final success rate dependent on definitions and quality of follow-up is shown in table 5. The table shows that success rates vary greatly depending on patient selection or exclusion, and whether intention-to-treat or outcome analysis are examined.

\section{DISCUSSION}

The present study represents the first assessment of long-term results of endotherapy for neoplastic $\mathrm{BO}$ based on a concept of widespread EMR aimed at complete BO eradication. On an intention-to-treat basis, about $85 \%$ of patients could achieve neoplasia-free and BO-free status based on two subsequent negative endoscopies and biopsies.

Strict follow-up criteria were subsequently used in the study resulting in the exclusion of 42 patients, most of whom had some long-term clinical follow-up information over several years, but no precise details about their endoscopic findings and/or they did not undergo biopsy because endoscopy was 
Table 1 Overview of patients treated by widespread endoscopic mucosal resection for neoplastic Barrett's oesophagus

\begin{tabular}{|c|c|}
\hline Age, mean (range), years & $63(35-82)$ \\
\hline Sex ratio, m:f & $82: 8(9: 1)$ \\
\hline \multicolumn{2}{|l|}{ Type of initial neoplasia } \\
\hline LGIN & 4 \\
\hline HGIN & 32 \\
\hline Cancer & 54 \\
\hline \multicolumn{2}{|l|}{ Mode of therapy, n (\%) } \\
\hline EMR alone & $38(42.2)$ \\
\hline EMR plus APC & $48(53.3)$ \\
\hline EMR plus RFA & $3(3.3)$ \\
\hline EMR plus APC plus RFA & $1(1.1)$ \\
\hline \multicolumn{2}{|l|}{ Number of sessions, mean (range) } \\
\hline EMR & $2.1(1-7)$ \\
\hline Additional APC $(n=48)$ & $1(1-4)$ \\
\hline Additional APC+RFA $(n=4)$ & $1(1-4)$ \\
\hline $\begin{array}{l}\text { Duration of primary treatment inclusive of all sessions, mean } \\
\text { (range), weeks }\end{array}$ & $73.4(38-132)$ \\
\hline Stricture development (requiring dilation), n (\%) & $43(47.8)$ \\
\hline Number of dilations (if applicable), mean (range) & $3.3(1-31)$ \\
\hline Duration of dilation therapy, mean (range), weeks & $7.9(1-46)$ \\
\hline \multicolumn{2}{|l|}{ Follow-up after completed therapy* } \\
\hline Duration, mean (range), months & $64.8(36-129)$ \\
\hline Number of endoscopies with biopsies, mean (range) & $6.4(1 \dagger-15)$ \\
\hline \multicolumn{2}{|c|}{$\begin{array}{l}\text { Of all } 179 \text { cases included in the analysis (intention to treat, data see text) } 90 \text { patients } \\
\text { formed the subgroup in whom complete Barrett's ablation was intended and } \\
\text { follow-up information available (see figure 1). } \\
{ }^{*} \text { Follow-up time was counted after either termination of ablation (EMR, APC) or, } \\
\text { if needed, additional dilation therapy. } \\
\text { tThe patient with only one follow-up had a normal endoscopy with normal biopsies } \\
85 \text { months after completion of endotherapy. } \\
\text { APC, argon plasma coagulation; EMR, endoscopic mucosal resection; HGIN, } \\
\text { high-grade intraepithelial neoplasia; LGIN, low-grade intraepithelial neoplasia; } \\
\text { RFA, radiofrequency ablation. }\end{array}$} \\
\hline
\end{tabular}

performed elsewhere and results were normal. It could be assumed, as has been in many other papers, that these patients did not develop visible or even symptomatic neoplasia, and that including them would have substantially increased our case number and, to some extent, also the success rate. However, it
Table 3 Patient and procedure characteristics by recurrence of BO or neoplasia

\begin{tabular}{|c|c|c|c|}
\hline & $\begin{array}{l}\text { No } \\
\text { recurrence } \\
n=44\end{array}$ & $\begin{array}{l}\text { Recurrence } \\
\mathrm{n}=37\end{array}$ & $\mathrm{p}$ Value \\
\hline Age, years & 62.4 & 63.0 & 0.782 \\
\hline Sex, male $\mathrm{n}(\%)$ & $41(93.2)$ & $33(89.2)$ & 0.697 \\
\hline Barrett's segment long, n (\%) & $9(20.5)$ & $15(40.5)$ & 0.049 \\
\hline Neoplasia grade, n (\%) & & & 0.343 \\
\hline Cancer & $23(52.3)$ & $24(64.9)$ & 0.253 \\
\hline HGIN or LGIN & $21(47.7)$ & $13(35.1)$ & 0.253 \\
\hline HGIN & $20(45.5)$ & $11(29.7)$ & 0.147 \\
\hline LGIN & $1(2.3)$ & $2(5.4)$ & 0.472 \\
\hline \multicolumn{4}{|l|}{ Type of treatment, $\mathrm{n}(\%)$} \\
\hline EMR & $19(43.2)$ & $14(37.8)$ & 0.626 \\
\hline Cap EMR & 6 & 3 & 0.518 \\
\hline Multiband ligation EMR & 6 & 7 & 0.284 \\
\hline Snare only (suck and cut) & 7 & 4 & 0.853 \\
\hline EMR+adjuvant & $25(56.8)$ & $23(62.2)$ & 0.626 \\
\hline $\mathrm{EMR}+\mathrm{APC}$ & $23(52.3)$ & $21(56.8)$ & 0.931 \\
\hline $\mathrm{EMR}+\mathrm{RFA}$ & $1(2.3)$ & $2(5.4)$ & 0.502 \\
\hline $\mathrm{EMR}+\mathrm{APC}+\mathrm{RFA}$ & $1(2.3)$ & 0 & 0.332 \\
\hline $\begin{array}{l}\text { Number of treatments, mean }( \pm S D) \text {, } \\
\text { months }\end{array}$ & $3.0(2.0)$ & $3.3(1.8)$ & 0.526 \\
\hline Stricture, n (\%) & $22(50.0)$ & $16(43.2)$ & 0.479 \\
\hline Duration of treatment $( \pm S D)$ & $6.1(7.4)$ & $8.5(10.3)$ & 0.229 \\
\hline $\begin{array}{l}\text { Duration of follow-up, mean }( \pm S D) \text {, } \\
\text { months }\end{array}$ & $67.1(22.7)$ & $65.9(21.0)$ & 0.402 \\
\hline Number of biopsies, mean $( \pm$ SD) & $6.1(4.1)$ & $6.3(4.6)$ & 0.858 \\
\hline
\end{tabular}

was decided to keep to the strict criteria because we were interested in the recurrence of neoplasia and Barrett's tissue after complete removal. Recurrence of Barrett's tissue, which is not always visible, can only be verified if biopsy results are available. However, in contrast with recent prospective studies, ${ }^{12}$ no

Table 2 Details of patients with recurrence of neoplasia following widespread endoscopic mucosal resection

\begin{tabular}{|c|c|c|c|c|c|}
\hline \multirow[b]{2}{*}{ Patient parameters } & \multicolumn{5}{|l|}{ Patient number } \\
\hline & 1 & 2 & 3 & 4 & 5 \\
\hline Age at initial therapy & 40 years & 66 years & 79 years & 61 years & 66 years \\
\hline Sex & Male & Male & Male & Male & Male \\
\hline Initial BO length & long $(4 \mathrm{~cm})$ & long $(4 \mathrm{~cm})$ & short & short & long $(5 \mathrm{~cm})$ \\
\hline Worst initial histology & $\begin{array}{l}\text { Adenocarcinoma } \\
\text { T1m3 G1 }\end{array}$ & $\begin{array}{l}\text { Adenocarcinoma } \\
\text { T1m3 G1 }\end{array}$ & $\begin{array}{l}\text { Adenocarcinoma } \\
\text { T1m3 G1 }\end{array}$ & HGIN & HGIN \\
\hline Therapy* & 2 EMR, 3 APC & 3 EMR, 2 APC & 3 EMR & $1 \mathrm{EMR}, 1 \mathrm{APC}$ & 2 EMR, 3 APC \\
\hline $\begin{array}{l}\text { Number of neg. } \\
\text { follow-up endoscopies }\end{array}$ & 6 & 4 & 5 & 7 & 3 \\
\hline $\begin{array}{l}\text { Recurrence histology } \\
\text { and location }\end{array}$ & $\begin{array}{l}\text { Adenocarcinoma, HGIN, LGIN, } \\
\text { in recurrent } \mathrm{BO} C 1 \mathrm{M} 2\end{array}$ & $\begin{array}{l}\text { Multiple HGIN (visible } \\
\text { BO islands) }\end{array}$ & $\begin{array}{l}\text { LGIN within buried gland in } \\
\text { recurrent } \mathrm{BO} \text { COM1 }\end{array}$ & $\begin{array}{l}\text { Adenocarcinoma at } \\
\text { neo-Z-line, histo BO }\end{array}$ & $\begin{array}{l}\text { Adenocarcinoma in sm } \\
\text { lesion at neo } Z \text { line }\end{array}$ \\
\hline Therapy for recurrence & $2 \mathrm{EMR}, 1 \mathrm{APC}$ & $1 \mathrm{EMR}, 1 \mathrm{APC}$ & $1 \mathrm{EMR}$ & $1 \mathrm{EMR}$ & 1 EMR \\
\hline Outcome & 1 neg. follow-up endoscopy & $\begin{array}{l}8 \text { neg. follow-up } \\
\text { endoscopies }\end{array}$ & $\begin{array}{l}5 \text { neg. follow-up } \\
\text { endoscopies }\end{array}$ & $\begin{array}{l}2 \text { neg. follow-up } \\
\text { endoscopies }\end{array}$ & $\begin{array}{l}1 \text { neg. follow-up } \\
\text { endoscopy }\end{array}$ \\
\hline
\end{tabular}

*Numbers denote number of sessions for each technique.

APC, argon plasma coagulation; BO, Barrett's oesophagus; EMR, endoscopic mucosal resection; HGIN, high-grade intraepithelial neoplasia; LGIN, low-grade intraepithelial neoplasia; RFA, radiofrequency ablation. 
Table 4 Association between recurrence of Barrett's epithelium or dysplasia and patient or procedure characteristics in univariate (crude OR) and multivariate (adjusted OR) analysis

\begin{tabular}{lll}
\hline & $\begin{array}{l}\text { Crude OR } \\
(95 \% \mathrm{Cl})\end{array}$ & $\begin{array}{l}\text { Adjusted OR } \\
(95 \% \mathrm{Cl})\end{array}$ \\
\hline Age & $1.01(0.96$ to 1.05$)$ & $1.01(0.97$ to 1.06$)$ \\
Sex & $1.66(0.34$ to 7.93$)$ & $1.75(0.33$ to 9.04$)$ \\
$\begin{array}{l}\text { Barrett's segment long } \\
\begin{array}{l}\text { Neoplasia grade (cancer vs } \\
\text { dysplasia) }\end{array}\end{array}$ & $\begin{array}{l}2.65(0.99 \text { to } 7.09) \\
\text { Type of treatment (EMR vs EMR }\end{array}$ & $2.73(1.01$ to 7.38$)$ \\
$\begin{array}{l}\text { +adjuvant) } \\
\text { Number of treatments (per }\end{array}$ & $1.25(0.51$ to 4.14$)$ & - \\
$\begin{array}{l}\text { additional treatment) } \\
\text { Duration of treatment (per }\end{array}$ & $1.08(0.86$ to 1.36$)$ & - \\
$\begin{array}{l}\text { additional month) } \\
\text { Number of biopsies during }\end{array}$ & $1.03(0.98$ to 10.09$)$ & - \\
follow-up & $1.01(0.90$ to 1.13$)$ & - \\
Length of follow-up & $1.00(0.98$ to 1.02$)$ & - \\
Stricture occurrence & $0.73(0.30$ to 1.76$)$ & - \\
\hline EMR, endoscopic mucosal resection. & &
\end{tabular}

systematic bioptic mapping below, at and above the neo $\mathrm{Z}$ line, as well as in the neosquamous epithelium, was performed (nor was the extent of submucosal tissue in biopsies known), so it cannot be excluded that the true complete $\mathrm{BO}$ eradication rate was lower. As a consequence, the recurrence rate after 'true' $\mathrm{BO}$ eradication could be lower if only cases without BO tissue after meticulous endoscopic bioptic screening were selected. However, our reanalysis of biopsy number and recurrences showed no significant correlation. On the other hand, some minimal residual sampling error can never be excluded, and from a clinical and pragmatic standpoint, the difference between recurrence de novo from a completely restored gastroesophageal junction and squamous epithelium and $\mathrm{BO}$ regrowth from minimal residual disease may not be so relevant. The conclusion that long-term follow-up should be extended beyond 5 years is still valid in our opinion. Most recurrences of BO-associated neoplasia, as well as non-neoplastic $\mathrm{BO}$, were found at the newly formed (neo) $\mathrm{Z}$ line. Therefore, this is in line with our recent results of subquamous $\mathrm{BO}$ tissue in almost every patient with (mostly neoplastic) $\mathrm{BO},{ }^{15}$ and clearly leads to recommendations to completely resect and/or ablade $\mathrm{BO}$ tissue into the cardia and squamous epithelium about $1 \mathrm{~cm}$. Whether this may really lead to a significantly lower long-term recurrence rate has, however, to be shown.

The present data demonstrate a high recurrence rate $(41 \%)$ even after complete widespread EMR. However, there are some limitations to this analysis, such as adopting two negative endoscopies with negative biopsies as a surrogate parameter for complete remission. This definition of complete BO eradication has been used in other studies ${ }^{16}$ and, in the absence of a surgical gold standard, probably represents the best surrogate parameter used in current practice. Sampling error could also account for missing small and possibly subsquamous areas of residual BO islands. In fact, in some cases, these were found intermittently during some of the follow-up endoscopies. The relevance of small residual non-dysplastic recurrent Barrett's tissue is not known. In general, patients with neoplastic lesions are known to have a high rate of metachronous lesions over time, so we have no good reason to believe that this should not also be the case with recurrent BO tissue after endotherapy. Thus, continued surveillance is indicated. Whether repeated ablative therapy confers any benefit to such patients with recurrent (non-dysplastic) BO compared with surveillance is not currently known. Similarly, the effect of proton pump inhibitors (PPI) on recurrence cannot fully be elucidated, since, although all patients were prescribed PPIs long-term after endotherapy, we do not have data on compliance.

In a small number of patients, residual $\mathrm{BO}$ was documented at the first endoscopic follow-up examination, yet, further follow-up endoscopies including biopsies failed to demonstrate persisting BO. It remains to be elucidated whether BO, in such cases, regresses spontaneously, or (more likely) whether this phenomenon is caused by sampling error, or lack of goblet cells and, therefore, inconsistencies in histopathological evaluation. Again, it currently remains unclear how such patients should be treated, and whether additional 'untargeted' ablation (ie, by RFA or APC) is necessary.

The rate of long-term neoplasia recurrence was less than $10 \%$ in the present study, which is higher than that in a previous
Figure 2 Example of a patient with focal neoplasia (T1m3 cancer) in a short Barrett oesophagus (upper left) treated by endoscopic mucosal resection (upper middle), and then, for residual disease (upper right) with one session of focal radiofrequency ablation (lower left), normal findings on 5 follow-up endoscopies (lower middle) including biopsy and then recurrence of a COM1 Barrett oesophagus without dysplasia after 1.5 years (lower right).
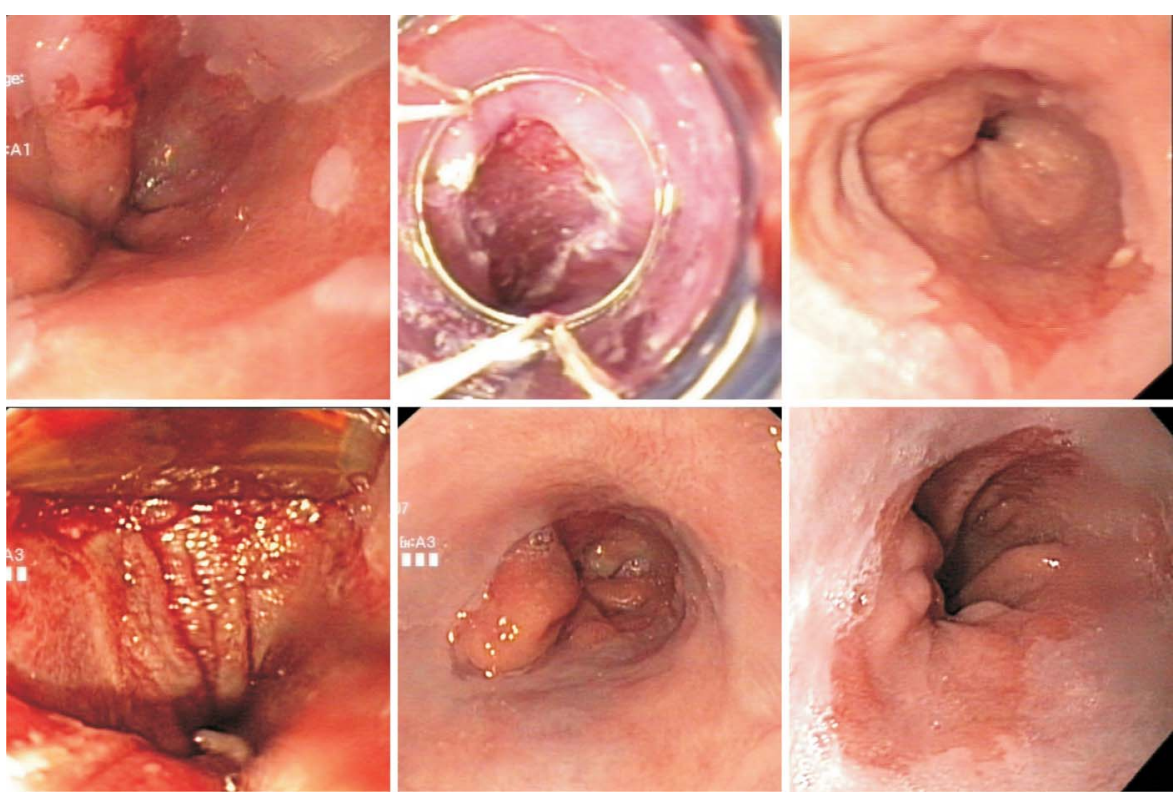
Figure 3 Example of a patient with focal neoplasia (high-grade intraepithelial neoplasia) in a short Barrett oesophagus (upper left) treated by endoscopic mucosal resection (upper middle), followed by argon plasma coagulation. Following dilatation, no residual Barrett could be found including negative biopsies on 5 follow-up endoscopies. Then recurrence was found after 44 months in a recurrent $1 \mathrm{~cm}$ Barrett tongue which was flat, slightly irregular and vulnerable (histology mucosal cancer) (lower two figures).

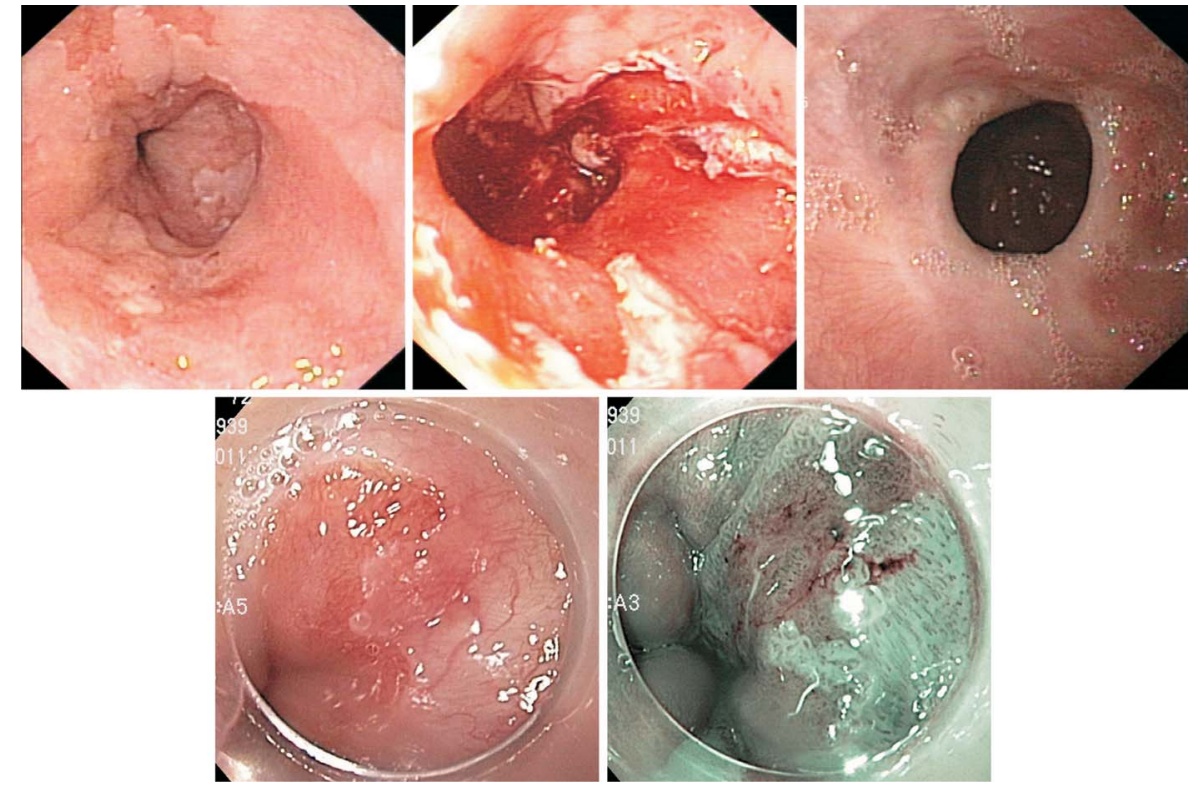

multicentre series with shorter follow-up. ${ }^{6}$ Notably, the five patients with recurrent neoplasia were all asymptomatic, and the lesion was only detected on routine follow-up, after variable but also long intervals. This clearly demonstrates the need for longterm follow-up beyond 5 years, based on our findings that very low rates of metachronous lesions within the first 2 years after endotherapy do not guarantee sustained disease-free periods. It might be that the reported lower frequency of recurrence in other series was due to shorter follow-up periods. ${ }^{7}$ 17-19

In this study, the treatment period was included in the 5-year follow-up period. Around the neo-Z-line, new (or residual) Barrett's tissue was found in $35 \%$ of cases, although to a very minor extent and of questionable relevance, since intestinal metaplasia may be difficult to differentiate from true BO. ${ }^{12}$ Furthermore, recurrence rates may be higher in registries including many and partially non-expert centres. Recurrence of nonneoplastic BO in our series was also of minor extent in most cases, but the fact of recurrent neoplasia after long intervals points towards some clinical relevance of minor residual $\mathrm{BO}$ tissue at least in patients with prior neoplastic BO.

Ablative thermal methods are known for recurrence rates of $30 \%$ or more. Similar to the small Dutch study cited above, ${ }^{12}$ larger recent registries have confirmed a high recurrence rate of BO after RFA. At 19 months of follow-up of patients $(n=335)$ included in a UK registry, recurrence of neoplasia and nondysplastic BO was detected in $9 \%$ each $^{10}$; however, incomplete follow-up places a high level of uncertainty over these results. In a US registry that initially included 592 cases, the 2-year recurrence rate of dysplastic and non-dysplastic $\mathrm{BO}$ was 33\%, and $22 \%$ harboured some form of neoplasia. ${ }^{11}$ In both series, $49 \%$ and $55 \%$, respectively, had undergone focal EMR before RFA. In the long-term follow-up of one randomised study, ${ }^{3}$ a 2 -year complete BO eradication rate of $93 \%$ was shown, but focal RFA was again used in 55\% after the 1-year endpoint, and only $38 \%$ of these therapies was based on histology. ${ }^{20}$ The present study was different from these as it mostly employed widespread EMR and used ablative methods (mostly APC) only for residual Barrett's tissue that was too small for additional resection sessions. However, the hypothesis that more radical tissue removal by resection (of mucosa and large parts of submucosa) instead of more or less superficial thermal ablation may lead to lower recurrence rates, proved not to be true. Furthermore, APC is often considered less effective than RFA in preventing recurrences, but there is no straightforward comparison, and in reviews, recurrences rates appear to be in the same range. ${ }^{21} \mathrm{~A}$ recent analysis of combined endotherapy also showed some mid-term recurrences, employing a mixture of resection, RFA and $\mathrm{APC} .^{22}$

Table 5 Outcome analysis according to treatment aim and patient selection (see also figure 1), n/N (\%)

\begin{tabular}{|c|c|c|}
\hline & $\begin{array}{l}\text { Free of } \\
\text { neoplasia }\end{array}$ & $\begin{array}{l}\text { Free of neoplasia and } \\
\text { Barrett epithelium }\end{array}$ \\
\hline ITT including all cases & $76 / 179(40.25)$ & $44 / 179(24.6)$ \\
\hline ITT excluding surgical cases but including cases without adequate follow-up* $(n=42)$ counted free of neoplasia & $76 / 138(55.1)$ & N/A \\
\hline $\begin{array}{l}\text { ITT excluding surgical cases and cases in whom complete ablation was not intended, but including all cases without } \\
\text { adequate follow-up* }(n=42) \text { counted free of neoplasia }\end{array}$ & $76 / 132(57.6)$ & N/A \\
\hline $\begin{array}{l}\text { ITT excluding surgical cases and cases in whom complete ablation was not intended, but including cases with some } \\
\text { follow-up* }(n=29) \text { counted free of neoplasia }\end{array}$ & $76 / 119(63.9)$ & N/A \\
\hline $\begin{array}{l}\text { ITT excluding surgical cases and cases in whom complete ablation was not intended, excluding cases without adequate } \\
\text { follow-up ( } n=42 \text { ) }\end{array}$ & $76 / 90(80.4)$ & $44 / 90(48.9)$ \\
\hline Cases with complete eradication, adequate follow-up (2 negative endoscopies/biopsies) & $76 / 81(93.8)$ & $44 / 81(54.3)$ \\
\hline
\end{tabular}

*Including at least two endoscopies with biopsies and a minimum of 3 years.

ITT, intention to treat; N/A, not assessable because endoscopic biopsy not done and/or results not available. 
Previous studies, mostly smaller and retrospective, are also in line with these findings of recurrence irrespective of the method applied. Recurrent neoplasia was noted in 11-26\% with median follow-up surveillance of more than 2 years using various forms of endotherapy. $569162023-26$

Interestingly, in some studies, recurrence occurred in cases with incomplete ablation of $\mathrm{BO}$ only. By contrast, the present study showed that even complete eradication does not guarantee long-lasting absence of metachronous neoplasia. The type of endoresection, or the method of Barrett eradication (resection only vs resection plus thermal ablation), did not have any influence on recurrence of $\mathrm{BO}$ and $\mathrm{BO}$-associated neoplasia; nevertheless, this question could only be sufficiently answered by prospective randomised trials; at least short-term efficacy was equal with resection versus combined endotreatment, with fewer side effects by the latter. ${ }^{12}$ This observation is underlined by our finding of malignancies recurring even after 5 years of follow-up. On the basis of this finding, it may be hypothesised that $\mathrm{BO}$ represents a chronic, potentially lifelong condition. Unfortunately, it remains unclear which patients develop recurrent disease and, therefore, require more intense surveillance. To date, long-segment Barrett's, piecemeal resection, lack of complete BO ablation after successful eradication of neoplasia, time to ablate $\mathrm{BO}>10$ months, and presence of multifocal neoplasia have been linked to the recurrence of neoplasia. ${ }^{59}$ In the present study, the only factor that was significantly associated with recurrence (taking neoplasia and non-dysplastic BO together) was the length of the Barrett's segment. By contrast, cases that were treated with widespread EMR plus ablative methods did not have higher recurrence rates in the univariate analysis.

These recurrence rates with respect to $\mathrm{BO}$ could be used as an argument for surgery, at least in younger patients. However, even esophagectomy for early Barrett's neoplasia does not guarantee non-recurrence of either BO or neoplasia, and has been shown in up to $18 \%$ of cases. ${ }^{27-31}$ Furthermore, recurrent BO was even found in up to $6 \%$ of patients who had undergone additional fundoplication after esophagectomy. ${ }^{32}$ Therefore, endoscopic surveillance needs to be performed in all patients following therapy of early neoplastic BO regardless of the type of previous therapy. Moreover, timely recognition of recurrent disease allows for repeat minimally invasive endotherapy, as demonstrated in the present study and in previous papers. ${ }^{5} 33$

Even though endotherapy is associated with a substantially lower percentage of complications compared with surgery, ${ }^{5}$ it is still associated with typical side effects. Oesophageal strictures represented the most frequent complication in the present study, as in previous studies. ${ }^{79} 2634$ In particular, strictures may occur in up $88 \%$ of cases following extensive resection. ${ }^{7}$ Although those strictures may be treated successfully by bougienage/dilation, they still require additional endoscopy sessions with the consequent risk of perforation.

The present study group included a substantial number of patients who required surgery after endotherapy. Inclusion of all patients who underwent initial endotherapy is not always reported in studies. In line with previous studies, the majority of these patients required esophagectomy as histopathological work-up of the EMR specimens revealed tumour invasion beyond the muscularis mucosae. ${ }^{9} 34$ This observation points to a central issue of endotherapy: the identification of suitable patients. Unfortunately, none of the currently available imaging techniques allows for sufficient discrimination between $\mathrm{BO}$ cancers limited to the muscularis mucosa (T1a) and those invading the submucosal layers (T1b). The infiltrative depth, however, represents the central surrogate marker to predict the risk of nodal spread and, thus, the limit of endotherapy use. It is common practice in many centres to perform EMR when endoscopy (and perhaps endosonography) suggests possible mucosal disease. ${ }^{35}$ Secondary surgery can then still be performed following interdisciplinary discussion with the patient.

Despite the rigid inclusion criteria adopted in the present study, the possibility of overlooking endoscopically unremarkable neoplasia cannot be fully ruled out. Furthermore, this study was a retrospective analysis, and a substantial number of patients had been lost to follow-up or were found to be unsuitable for further endotherapy as discussed above. Nevertheless, the study showed that endotherapy represents a safe and effective modality to treat early neoplastic $\mathrm{BO}$ and confirmed the results of previous studies: neoplasia progression can be prevented and more than $90 \%$ of patients remain neoplasia free at 5 years. More importantly, however, the present data clearly underline the need for long-term endoscopic follow-up for a period longer than 5 years.

\section{Author affiliations}

${ }^{1}$ Department of Interdisciplinary Endoscopy, University Hospital Hamburg-Eppendorf, Hamburg, Germany

${ }^{2}$ Division of Gastroenterology, Department of Internal Medicine, Assiut University, Assiut, Egypt

${ }^{3}$ Department of Pathology, University Hospital Hamburg-Eppendorf, Hamburg, Germany

${ }^{4}$ Department of Pathology, Charité University Hospital, Berlin, Germany

${ }^{5}$ Gastrozentrum, Hirslanden Clinic, Zürich, Switzerland

${ }^{6}$ Department of Gastroenterology, Charité University Hospital, Berlin, Germany

${ }^{7}$ Department of Surgery, University Hospital Hamburg-Eppendorf, Hamburg, Germany

${ }^{8}$ Department of Surgery, Charité University Hospital, Berlin, Germany

${ }^{9}$ VA Medical Center, White River Junction, Vermont, USA

Contributors MA performed some of the examinations, was involved in data analysis and paper writing; CB and MAE-M were responsible for data collection and analysis; AM and MK undertook histopathological assessment of biopsies and resection specimens; SS, GS, AA and NS were responsible for the study interventions, and JI and PN for the surgical treatments; HP performed the statistical analyses; and TR was responsible for the study concept and planning, data collection supervision, data analysis and paper writing. The paper was seen and approved by all coauthors.

\section{Competing interests None.}

Patient consent Obtained.

Ethics approval Ethical Committee of the Hamburg Chamber of Physicians.

Provenance and peer review Not commissioned; externally peer reviewed.

\section{REFERENCES}

1 Hvid-Jensen F, Pedersen L, Drewes AM, et al. Incidence of adenocarcinoma among patients with Barrett's esophagus. N Engl J Med 2011;365:1375-83.

2 Bollschweiler E, Wolfgarten E, Gutschow C, et al. Demographic variations in the rising incidence of esophageal adenocarcinoma in white males. Cancer 2001;92:549-55.

3 Shaheen NJ, Sharma P, Overholt BF, et al. Radiofrequency ablation in Barrett's esophagus with dysplasia. N Engl J Med 2009;360:2277-88.

4 Stein $\mathrm{HJ}$, Feith $\mathrm{M}$, Bruecher BL, et al. Early esophageal cancer: pattern of lymphatic spread and prognostic factors for long-term survival after surgical resection. Ann Surg 2005;242:566-73.

5 Pech $\mathrm{O}$, Bollschweiler $\mathrm{E}$, Manner $\mathrm{H}$, et al. Comparison between endoscopic and surgical resection of mucosal esophageal adenocarcinoma in Barrett's esophagus at two high-volume centers. Ann Surg 2011:254:67-72.

6 Pouw RE, Seewald S, Gondrie JJ, et al. Stepwise radical endoscopic resection for eradication of Barrett's oesophagus with early neoplasia in a cohort of 169 patients. Gut 2010;59:1169-77.

7 van Vilsteren FGI, Pouw RE, Seewald S, et al. Stepwise radical endoscopic resection versus radiofrequency ablation for Barrett's oesophagus with high-grade dysplasia or early cancer: a multicentre randomised trial. Gut 2011;60:765-73.

8 Bennett C, Vakil N, Bergman J, et al. Consensus statements for management of Barrett's dysplasia and early-stage esophageal adenocarcinoma, based on a Delphi process. Gastroenterology 2012;143:336-46. 
9 Pech 0, Behrens A, May A, et al. Long-term results and risk factor analysis for recurrence after curative endoscopic therapy in 349 patients with high-grade intraepithelial neoplasia and mucosal adenocarcinoma in Barrett's oesophagus. Gut 2008; 57:1200-6.

10 Haidry RJ, Dunn JM, Butt MA, et al. Radiofrequency Ablation (Rfa) and endoscopic mucosal resection for dysplastic Barrett's esophagus and early esophageal adenocarcinoma: outcomes of UK National Halo RFA Registry. Gastroenterology 2013;145:87-95

11 Gupta M, lyer PG, Lutzke L, et al. Recurrence of esophageal intestinal metaplasia after endoscopic mucosal resection and radiofrequency ablation of Barrett's esophagus: results from a US multicenter consortium. Gastroenterology 2013;145:79-86.

12 Phoa KN, Pouw RE, van Vilsteren FG, et al. Remission of Barrett's esophagus with early neoplasia 5 years after radiofrequency ablation with endoscopic resection: a Netherlands cohort study. Gastroenterology 2013;145:96-104.

13 Inoue $\mathrm{H}$, Takeshita $\mathrm{K}$, Hori $\mathrm{H}$, et al. Endoscopic mucosal resection with a cap-fitted panendoscope for esophagus, stomach, and colon mucosal lesions. Gastrointest Endosc 1993;39:58-62.

14 Soehendra N, Seewald S, Groth S, et al. Use of modified multiband ligator facilitates circumferential EMR in Barrett's esophagus (with video). Gastrointest Endosc 2006:63:847-52.

15 Anders M, Lucks Y, El-Masry MA, et al. Subsquamous extension of intestinal metaplasia is detected in 98\% of cases of neoplastic Barrett's esophagus. Clin Gastroenterol Hepatol Published Online First: 25 Jul 2013. doi:10.1016/j.cgh.2013.07.013

16 Ell C, May A, Pech 0, et al. Curative endoscopic resection of early esophageal adenocarcinomas (Barrett's cancer). Gastrointest Endosc 2007;65:3-10

17 Peters FP, Kara MA, Rosmolen WD, et al. Stepwise radical endoscopic resection is effective for complete removal of Barrett's esophagus with early neoplasia: a prospective study. Am J Gastroenterol 2006;101:1449-57.

18 Neuhaus H, Terheggen G, Rutz EM, et al. Endoscopic submucosal dissection plus radiofrequency ablation of neoplastic Barrett's esophagus. Endoscopy 2012:44:1105-13.

19 Pouw RE, Wirths K, Eisendrath P, et al. Efficacy of radiofrequency ablation combined with endoscopic resection for barrett's esophagus with early neoplasia. Clin Gastroenterol Hepatol 2010;8:23-9.

20 Shaheen NJ, Overholt BF, Sampliner RE, et al. Durability of radiofrequency ablation in Barrett's esophagus with dysplasia. Gastroenterology 2011;141:460-8.

21 Menon D, Stafinski T, Wu H, et al. Endoscopic treatments for Barrett's esophagus: a systematic review of safety and effectiveness compared to esophagectomy. BMC Gastroenterol 2010;10:111.
22 Guarner-Argente C, Buoncristiano T, Furth EE, et al. Long-term outcomes of patients with Barrett's esophagus and high-grade dysplasia or early cancer treated with endoluminal therapies with intention to complete eradication. Gastrointest Endosc 2013;77:190-9.

23 Pech 0, Gossner L, May A, et al. Long-term results of photodynamic therapy with 5-aminolevulinic acid for superficial Barrett's cancer and high-grade intraepithelial neoplasia. Gastrointest Endosc 2005;62:24-30.

24 Behrens A, May A, Gossner L, et al. Curative treatment for high-grade intraepithelia neoplasia in Barrett's esophagus. Endoscopy 2005;37:999-1005.

25 Overholt BF, Wang KK, Burdick JS, et al. Five-year efficacy and safety of photodynamic therapy with Photofrin in Barrett's high-grade dysplasia. Gastrointest Endosc 2007:66:460-8.

26 Prasad GA, Wang KK, Buttar NS, et al. Long-term survival following endoscopic and surgical treatment of high-grade dysplasia in Barrett's esophagus. Gastroenterology 2007;132:1226-33.

27 Chaves $P$, Pereira AD, Cruz $C$, et al. Recurrent columnar-lined esophageal segments--study of the phenotypic characteristics using intestinal markers. Dis Esophagus 2002;15:282-6

28 Leers JM, DeMeester SR, Ayazi S, et al. Recurrence of intramucosal esophageal adenocarcinoma arising in a former esophagostomy site: a unique case report. Dis Esophagus 2009:22:E17-20.

29 Peyre CG, DeMeester SR, Rizzetto C, et al. Vagal-Sparing Esophagectomy. Ann Surg 2007;246:665-74.

30 Rice TW, Murthy SC, Mason DP, et al. Esophagectomy for clinical high-grade dysplasia. Eur J Cardiothorac Surg 2011;40:113-19.

31 Wolfsen HC, Hemminger LL, Devault KR. Recurrent Barrett's esophagus and adenocarcinoma after esophagectomy. BMC Gastroenterol 2004;4:18.

32 Tsiouris A, Hammoud Z, Velanovich V. Barrett's esophagus after resection of the gastroesophageal junction: effects of concomitant fundoplication. World J Surg 2011:35:1867-72

33 Prasad GA, Wu TT, Wigle DA, et al. Endoscopic and surgical treatment of mucosal (T1a) esophageal adenocarcinoma in Barrett's esophagus. Gastroenterology 2009;137:815-23.

34 Chennat J, Konda VJA, Ross AS, et al. Complete Barrett's eradication endoscopic mucosal resection: an effective treatment modality for high-grade dysplasia and intramucosal carcinoma--an American single-center experience. Am J Gastroenterol 2009;104:2684-92

35 Manner H, May A, Pech O, et al. Early Barrett's carcinoma with 'low-risk' submucosal invasion: long-term results of endoscopic resection with a curative intent. Am J Gastroenterol 2008;103:2589-97. 